\title{
STRUKTUR DAN KOMPOSISI FITOPLANKTON DI BAGIAN TENGAH DAN HILIR SUNGAI SALUESEM - SULAWESI UTARA
}

\author{
Jeane O.K.Tiwow ${ }^{1)}$, Herni E.I. Simbala ${ }^{1)}$, Sendy Rondonuwu ${ }^{1)}$, Ratna Siahaan ${ }^{1)}$ \\ 1) Jurusan Biologi FMIPA Universitas Sam Ratulangi Manado \\ e-mail: jeinetiwow.jt@gmail.com; hsimbala@yahoo.co.id; rondonuwu64@yahoo.com; \\ Ratna245_siahaan@yahoo.com
}

\begin{abstract}
ABSTRAK
Sungai Saluesem berasal dari Gunung Mahawu melintasi Kota Manado sebelum bermuara di Teluk Manado, Sulwesi Utara. Penelitian dilakukan di bagian tengah dan hilir Sungai Salueseum, Sulawesi Utara dari April hingga November 2014. Penelitian ini bertujuan untuk menganalis ke struktur dan komposisi fitoplankton di bagian tengah dan hilir Sungai Saluesem, Sulawesi Utara. Penelitian menggunakan metode purposive random sampling untuk menentukan lokasi penelitian. Dua stasiun penelitian disebarkan di tiap bagian sungai. Sebanyak tiga ulangan dilakukan di tiap stasiun. Total banyaknya sampel yaitu dua belas $(2 \times 2 \times 3)$ sampel yang diperoleh dengan plankton net ukuran 30 mesh. Hasil penelitian menunjukkan bahwa fitoplankton yang didapatkan di bagian tengah Sungai Saluesem sebanyak 399 individu, 28 spesies dan 3 kelas. Fitoplankton yang didapatkan di bagian hilir Sungai Saluesem sebanyak 913 individu, 26 spesies dan 4 kelas. Kelas fitoplankton yaitu Bacillariophyceae, Chlorophyceae dan Cyanophyceae dan Euglenophyceae. Kelas Bacillariophyceae merupakan kelas yang memiliki kepadatan tertinggi di bagian tengah dan hilir berturut-turut yaitu 4067 individu $/ \mathrm{m}^{3}(81 \%)$ dan 14950 individu $/ \mathrm{m}^{3}$ (95\%). Indeks keanekaragaman di bagian tengah dan hilir termasuk keanekaragaman sedang dengan nilai $\mathrm{H}^{\prime}$ bagian tengah $\left(H^{\prime}: 2,88\right)$ dan hilir $\left(H^{\prime}: 2,64\right)$. Distribusi species fitolankton di bagian tengah dan hilir merata dengan Indeks Kemerataan (E) berturut-turut yaitu 0,87 dan 0,81. Tidak ada species fitoplankton di bagian tengah yang mendominansi dengan nilai Indeks Dominansi (D) mendekati nol $(0,222)$. Beberapa species fitoplankton di bagian hilir mendominansi dengan nilai Indeks D mendekati satu $(0,544)$. Kualitas air Sungai Saluseum di bagian tengah dan hilir dikategorikan tercemar ringan.
\end{abstract}

Kata kunci : Sungai Saluesem, struktur fitoplankton, komposisi fitoplankton, kualitas air, Sulawesi Utara.

\section{STRUCTURE AND COMPOSITION OF PHYTOPLANKTON OF MIDDLE AND DOWNSTREAM SALUESEUM RIVER, NORTH SULAWESI}

\begin{abstract}
Saluesem River originated from Mahawu Mount crosses the Manado City before down to Manado Bay, North Sulwesi. The study was conducted in the middle and lower part of Salueseum River, North Sulawesi from April to November 2014. This study aims to analyze the structure and composition of the phytoplankton at the middle and lower part of the River Saluesem, North Sulawesi. Research used purposive random sampling to choose researc locations. Two research stations were distributed in each part of the river. A total of three replications performed at each station. The total number of samples that were twelve $(2 \times 2 \times 3)$ samples by plankton net 30 mesh. The results showed that phytoplankton at the middle as 399 individuals, 28 species and 3 classes. Phytoplankton were at down as 913 individuals, 26 species and 4 classes i.e. Bacillariophyceae, Chlorophyceae and Cyanophyceae and Euglenophyceae. Bacillariophyceae has the highest density at the middle and downstream respectively were 4067 individuals $/ \mathrm{m}^{3}(81 \%)$ and 14950 individuals $/ \mathrm{m}^{3}(95 \%)$. Diversity index $\left(\mathrm{H}^{\prime}\right)$ at middle and downstream were classified into middle diversity with index respectively 2.88 and 2.64. Evenness index (E) at middle and down
\end{abstract}


respectively were 0.87 and 0.81 showed that phytoplankton distributed equally. Some species at middle were dominant (D:0.222) but not at downstream (D: 0,544). Water quality of middle and downstream Saluseum River were classified into light pollution.

Keyword: Saluesem River, structure phytoplankton, composition phytoplankton, water quality, North Sulawesi.

\section{PENDAHULUAN}

Sungai adalah suatu ekosistem yang mengalir dalam sistem perairan yang terbuka dan menerima limpasan daratan sepanjang aliran sungai (Odum, 1996). Oleh karena itu, kualitas air sungai dipengaruhi oleh aktivitas manusia di daerah aliran sungai.

Fitoplankton adalah mikroorganisme yang hidup melayang di dalam air dan mampu berfotosintesis. Fitoplankton dapat ditemukan di seluruh massa air mulai dari permukaan sampai kedalaman dimana intensitas cahaya matahari masih memungkinkan untuk digunakan dalam proses fotosintesis (Nontji, 2008). Fungsi ekologis fitoplankton di sungai sebagai produsen primer dalam rantai makaanan di sungai. Fitoplankton dimakan zooplankton dan beberapa jenis ikan serta larva biota yang masih muda. Keanekeragaman fitoplankton di sungai dapat digunakan sebagai paramter biologid untuk mengevaluasi kualitas air sungai (Astriyana dan Yuliana, 2012).

Sungai Salueem merupakan sungai yang dimanfaatkan penduduk sebagai sumber air minum. Akivitas manusia di sekitar Sungai Saluesem dapat mempengaruhi struktur dan komposisi fitoplankton. Perubahan ini dapat berdampak pada kualitas air Sungai Saluesem. Penelitian tentang struktur dan komposisi fitoplankton di bagian tengah dan hilir Sungai Saluesem belum pernah dilaporkan. Penelitian ini berujuan untuk menganalisis struktur dan komposisi fitoplankton di bagian tengah dan hilir Sungai Saleusem - Sulawesi Utara.

\section{METODE PENELITIAN}

Penelitian ini dilaksanakan di bagian tengah dan hilir Sungai Saluesem, Sulawesi Utara dari April hingga November 201. Sebanyak dua (2) stasiun pengamatan disebar masing-masing di bagian tengah dan hilir. Sejumlah tiga (3) titik pengamatan ditentukan di tiap stasiun pengamatan. Identifikasi fitoplankton dilakukan di Laboratorium
Ekologi, Jurusan Biologi, Fakultas Matematika dan Ilmu Pengetahuan Alam, Universitas Sam Ratulangi Manado. Pengukuran nitrat dan fosfat dilakukan di Laboratorium Balai Riset dan Standarisasi Industri Manado (Baristrand - Manado).

Alat yang digunakan antara lain plankton net ukuran 30 mesh, mikroskop digital berkamera dan Sedgewick-Rafter. Bahan yang digunakan yaitu larutan lugol dan terusi. Identifikasi dengan menggunakan pustaka Prescott (1978), Edmonson (1966), Sachlan (1982), van den Hoek et al.(1995) dan Bold dan Wynne (1985).

Metode purposive random sampling digunakan dalam menentukan titik-titik pengamatan. Total sampel fitoplankton di tengah dan hilir berjumlah duabelas (12) sampel. Sampel fitoplankton diperoleh dengan menyaring air sungai dengan plankton net yang diletakkan di dasar sungai menghadap arah datangnya arus selama lima (5) menit. Sampel fitoplankton yang sudah tersaring kemudian dimasukkan ke dalam botol sampel dan diawetkan dengan larutan lugol dan terusi. Parameter lingkungan yang diukur yaitu suhu, $\mathrm{pH}$, kecerahan, nitrat dan total fosfat.

Struktur dan kompisi yang dianalisis yaitu kelimpahan, kekayaan jenis, distribusi, kepadatan, keanekaragaman, kemerataan dan dominansi. Kepadatan fitoplankton diketahui dengan menggunakan rumus dari Wardhana (2003) yaitu: dengan:

$$
\mathrm{D}=(\mathrm{L} / \mathrm{p}) \mathrm{q}(1 / \mathrm{v})
$$

D : Kepadatan fitoplankton persatuan volume (indiv $/ \mathrm{m}^{3}$ )

$\mathrm{q}:$ Jumlah fitoplankton

$\mathrm{p}$ : Volume sampel dalam Sedgewick-

Rafter (ml)

$\mathrm{L}$ : Volume sampel yang tersaring (ml)

$\mathrm{v}$ : Volume air yang masuk dalam planktonet $\left(\mathrm{m}^{3}\right)$

Keanekaragaman fitoplankton dihitung dengan menggunakan indeks 
keanekaragaman Shannon-Wiener

Magurran, 2004) yaitu:

dengan :

$$
\mathrm{H}^{\prime}=-\Sigma\left(\mathrm{p}_{\mathrm{i}} \ln \mathrm{p}_{\mathrm{i}}\right)
$$

H' : Indeks Keanekaragaman Spesies

$\mathrm{p}_{\mathrm{i}}$ : Ideks Nilai Penting species ke- $\mathrm{i}$ per Indeks Nilai Penting total (ni/N)

$\mathrm{n}_{\mathrm{i}}$ : Indeks Nilai Penting spesies ke- $\mathrm{i}$

$\mathrm{N}$ : Indeks Nilai Penting Total

Nilai Penting: Kelimpahan Relatif +

Kepadatan Relatif

Indeks keanekaragaman (H') menurut

Staub et al (1970) digunakan untuk menentukan kualitas air sungai. Nilai $\mathrm{H}^{\prime}$ jika air tercemar berat (0-1), sedang (1-2), ringan (2-3), sangat ringan (3-4,5) (Wilhm, 1975).

Indeks kemerataan (Evenness)

fitoplankton ditentukan dengan rumus sebagai berikut (Odum, 1996).

$$
\mathrm{E}=\mathrm{H}^{\prime} / \ln \mathrm{S}
$$

dengan :

E : Indeks Kemerataan

$\mathrm{H}^{\prime} \quad$ : Indeks Keanekaragaman

$\mathrm{S}$ : Banyaknya species total

Indeks dominansi Simpson dihitung menggunakan rumus berikut ini (Odum, 1996):

$\mathrm{D}=\Sigma\left(\mathrm{n}_{\mathrm{i}} / \mathrm{N}\right)^{2}$

dengan :

D : Indeks dominansi Simpson

$\mathrm{n}_{\mathrm{i}}$ : Jumlah individu species ke-i

$\mathrm{N}$ : Jumlah individu semua species

dalam komunita

\section{HASIL DAN PEMBAHASAN}

\section{Kekayaan dan Kelimpahan Species Fitoplankton}

Fitoplankton di bagian tengah dan hilir Sungai Saluesem berturut-turut berjumlah 28 dan 26 species. Fitoplankton di bagian tengah terbagi dalam tiga (3 kelas) yaitu Bacillariophyceae, Chlorophyceae dan Cyanophyceae. Fitoplankton yang ditemukan di bagian hilir sungai ada dalam empat (4 kelas) yaitu Bacillariophyceae, Chlorophyceae, Cyanophyceae dan Euglenohyceae.

Fitoplankton di bagian tengah Stasiun I dan Stasiun II ditemukan 335 individu, 28 spesies dan 462 individu, 28 spesies. Peningkatan kelimpahan fitoplankton terjadi di bagian hilir yaitu pada Stasiun I dan II berturut-turut yaitu 963 dan 858 individu.
Peningkatan kelimpahan individu ini diiringi dengan penurunan kekayaan species dari tengah ke hilir. Kekayaan species di hilir pada Stasiun I dan II berturut-turut yaitu 25 dan 24 species.

\section{Distribusi Fitoplankton}

Distribusi fitoplankton di bagian tengah sebanyak 28 species dan di bagian hilir Sungai Saluesem berjumlah 26 species . Kekayaan species (S) fitoplankton yang ditemukan di kedua stasiun di bagian berjumlah yaitu 28 species. Kekayaan species fitoplankton di bagian hilir tidak sama yaitu 25 species di Stasiun I dan 24 species di Stasiun II seperti dalam Tabel 1.

Fitoplankton Euglena sp. terdistribusi terbatas hanya ditemukan di Stasiun II bagian hilir. Kelas Bacillariophyceae ditemukan di bagian tengah dan hilir kecuali Coconeis sp. Kelas Cholorophyceae ditemukan di bagian tengah dan hilir kecuali Ankistrodesmus sp. dan Scenedesmus sp. Kelas Cyanophyceae tersebar luas dan daat ditemukan di kedua bagian tengah dan hilir Sungai Saluesem.

\section{Kepadatan Fitoplankton}

Kepadatan fitoplankton dari Kelas Bacillariophyceae menempati urutan pertama di bagian tengah Sungai Saluesem yaitu 4067 individu $/ \mathrm{m}^{3}(81 \%)$. Kelas Chlorophyceae merupakan kelas kedua terpadat yaitu 634 individu $/ \mathrm{m}^{3}(13 \%)$. Urutan ketiga ditempati Kelas Chlorophyceae dengan kepadatan 312 individu $/ \mathrm{m}^{3}(6 \%)$. Fitoplankton di bagian hilir hampir seluruhnya merupakan fitoplankton dari Kelas Bacillariophyceae dengan kepadatan 14950 individu $/ \mathrm{m}^{3}$ (95\%). Sisanya termasuk Kelas Chlorophyceae, Cyanophyceae dan Euglenophyceae. Kepadatan fitolankton di bagian tengah dan hilir Sungai Saluesem tampak pada Gambar 1.

Kelas Bacillariophyceae merupakan kelas dengan kepadatan tertinggi baik di bagian tengah maupun di bagian hilir Sungai Sauesem. Kelompok diatom (Kelas Bacillariophyceae) merupakan kelompok fitoplankton yang paling banyak dijumpai di perairan. Kelompok ini memiliki kemampuan yang baik untuk beradaptasi dengan kondisi lingkungan yang ada di sekitarnya sehingga memiliki penyebaran yang luas (Nontji, 2008). Spesies yang memiliki kepadatan tertinggi di kedua bagian sungai yaitu 
Synedra sp yang termasuk dalam Kelas Bacillariophyceae.

Tabel 1.Distribusi Fitoplankton pada Lokasi Penelitian

\begin{tabular}{|c|c|c|c|c|c|}
\hline \multirow[t]{2}{*}{ No. } & \multirow[t]{2}{*}{ Taksa } & \multicolumn{2}{|c|}{ Tengah } & \multicolumn{2}{|c|}{ Hilir } \\
\hline & & Stasiun I & Stasiun II & Stasiun I & Stasiun II \\
\hline 1. & Achnanthes sp. & + & + & + & + \\
\hline 2. & Actinastrum sp. & + & + & + & + \\
\hline 3. & Anabaena sp. & + & + & + & + \\
\hline 4. & Ankistrodesmus sp. & + & + & - & - \\
\hline 5. & Closterium sp1. & + & + & + & + \\
\hline 6. & Closterium sp2. & + & + & + & + \\
\hline 7. & Coconeis sp. & + & + & - & - \\
\hline 8. & Coscinodiscus sp. & + & + & + & + \\
\hline 9. & Cosmarium sp. & + & + & + & + \\
\hline 10. & Cymbella sp. & + & + & + & + \\
\hline 11. & Euglena sp. & - & - & + & - \\
\hline 12. & Fragilaria sp. & + & + & + & + \\
\hline 13. & Girosikma sp. & + & + & + & + \\
\hline 14. & Kentrosphaera sp. & + & + & + & - \\
\hline 15. & Microspora sp. & + & + & + & + \\
\hline 16. & Mougeotia sp. & + & + & + & + \\
\hline 17. & Navicula sp 1. & + & + & + & + \\
\hline 18. & Navicula sp 2. & + & + & + & + \\
\hline 19. & Oscillatoria sp & + & + & + & + \\
\hline 20. & Pinnularia sp. & + & + & + & + \\
\hline 21. & Pleurosigma sp. & + & + & + & + \\
\hline 22. & Pseudanabaena sp. & + & + & + & + \\
\hline 23. & Scenedesmus sp & + & + & - & - \\
\hline 24. & Spirogyra sp. & + & + & + & + \\
\hline 25. & Spirulina sp. & + & + & - & + \\
\hline 26. & Surirella sp. & + & + & + & + \\
\hline 27. & Synedra sp. & + & + & + & + \\
\hline 28. & Terpsinoe sp. & + & + & + & + \\
\hline 29. & Ulothrix sp. & + & + & + & + \\
\hline & $\mathrm{S}$ & 28 & 28 & 25 & 24 \\
\hline
\end{tabular}

Keterangan: + : ditemukan; -: tidak ditemukan; S: kekayaan species

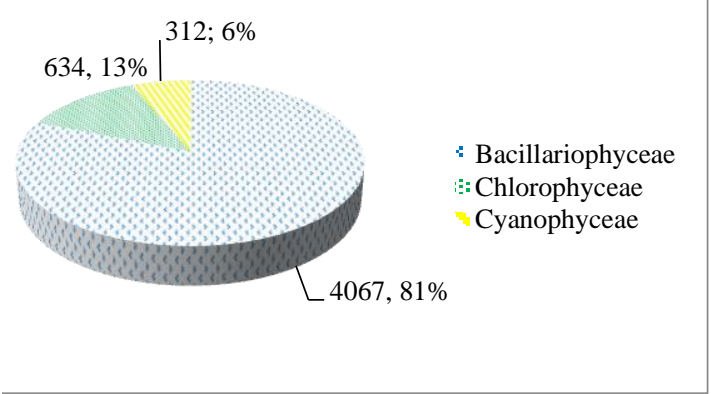

a. Bagian Tengah

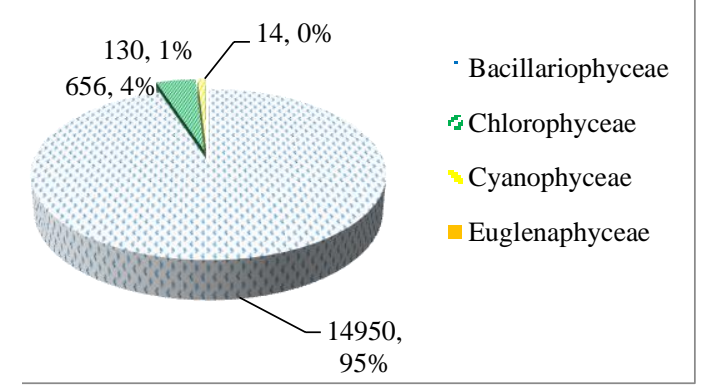

b. Bagian Hilir

Gambar 1.Kepadatan fitolankton di bagian tengah dan hilir Sungai Saluesem 


\section{Keanekaragaman Fitoplankton}

Keanekaragman fitoplankton di Sungai Salueseum dinyatakan dengan Indeks Keanekaragaman Shannon-Wiener (H'). Nilai H' pada kedua stasiun pengambilan di bagian tengah yaitu Stasiun I (H': 2,89$)$ dan Stasiun II (H': 2,86). Indeks keanekaragaman di bagian tengah yaitu $H^{\prime}: 2,88$. Nilai $H^{\prime}$ di bagian hilir pada Stasiun I (H': 2,65) dan Stasiun II (H': 2,63). Indeks keanekaragaman di bagian hilir yaitu H': 2,64 (Gambar 2). Berdasarkan kriteria Fachrul (2007), Indeks keanekaragaman di bagian tengah dan hilir termasuk keanekaragaman sedang $\left(2 \leq \mathrm{H}^{\prime} \leq 3\right)$.

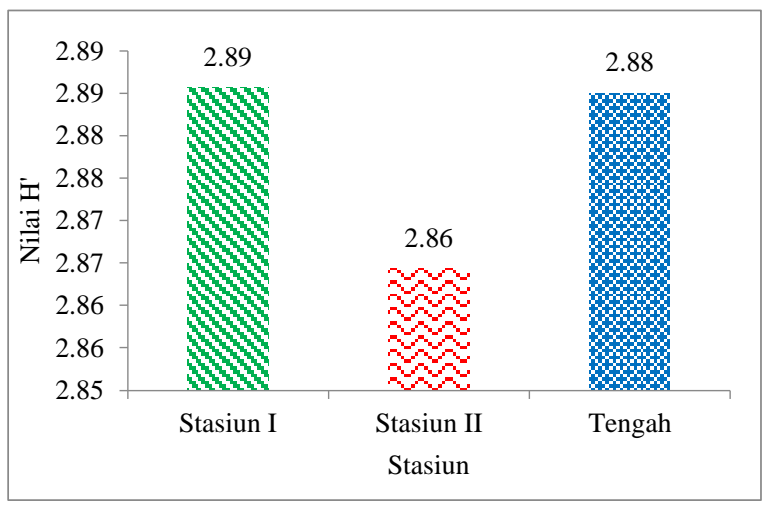

a. bagian tengah

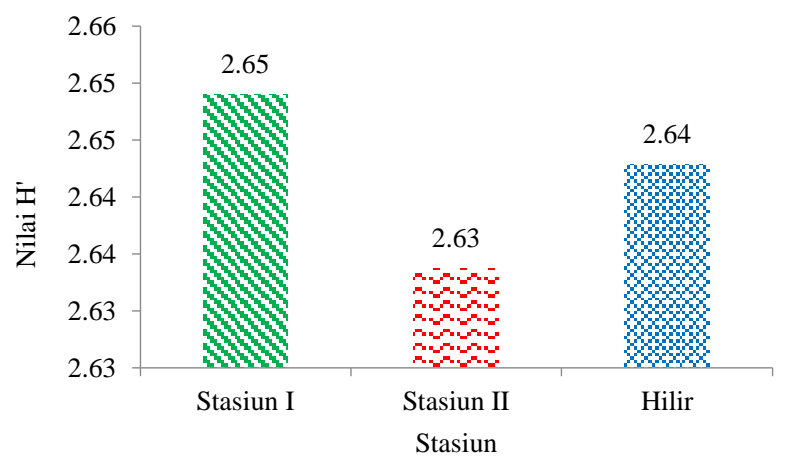

b. bagian hilir

Gambar 2. Indeks Keanekaragaman

fitoplankton di Sungai Saluesem Bagian Hilir

\section{Kemerataan Fitoplankton}

Indeks kemerataan (E) fitoplankton di

Stasiun I dan Stasiun II bagian tengah berturut-turut yaitu 0,88 dan 0,86 . Indeks kemerataan di bagian tengah Sungai Saluesem yaitu 0,87. Indeks kemerataan Saluesem di bagian hilir yaitu Stasiun I dan Stasiun II yaitu 0,82 dan 0,83 . Indeks kemerataan di bagian hilir Sungai Saluesem yaitu 0,81 (Gambar 3). Nilai indeks kemeratan di perairan Sungai Saluesem bagian tengah dan hilir mendekati angka 1 yang menunjukkan bahwa distribusi spesies fitoplankton yang merata atau distribusi tiap spesies tidak jauh berbeda.
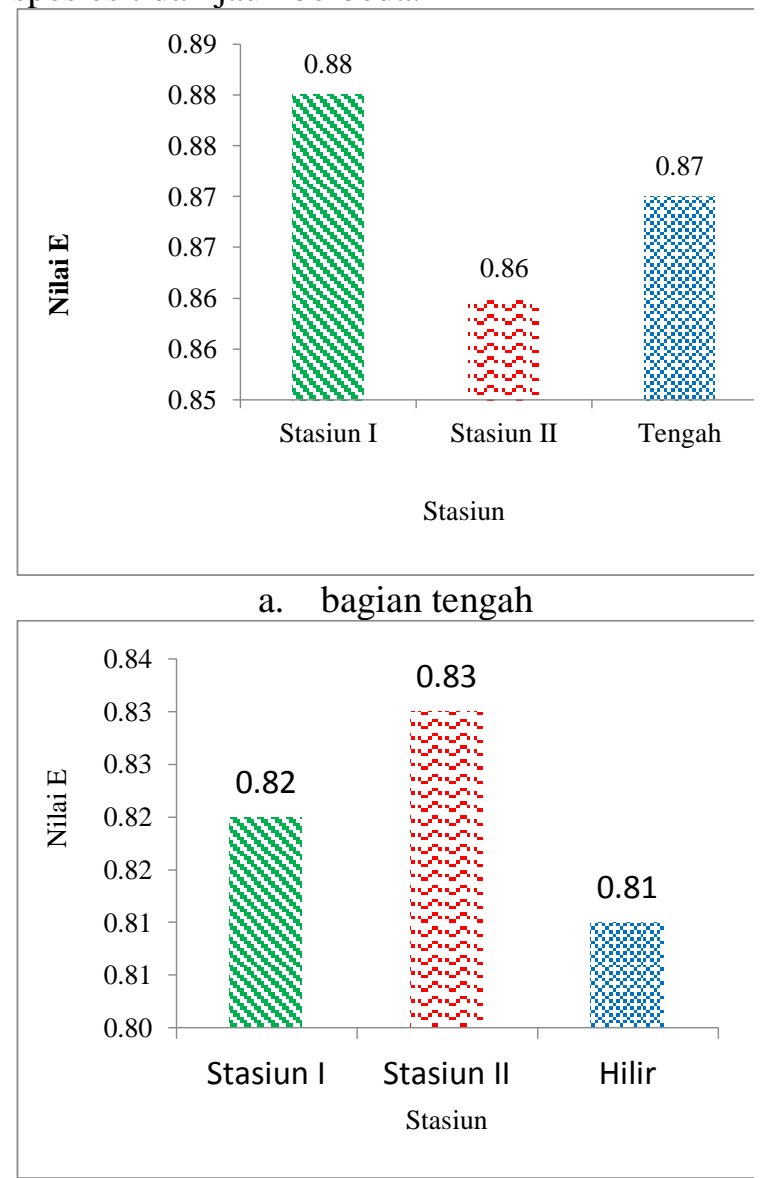

b. bagian hilir

Gambar 3. Indeks Kemerataan Fitoplankton di Bagian Tengah dan Hilir Sungai Saluesem

\section{Dominansi Fitolankton}

Nilai indeks dominansi (D)

fitoplankton di bagian tengah yaitu Stasiun I $(0,216)$ dan Stasiun II $(0,232)$. Nilai Indeks dominansi fitoplankton di bagian tengah Sungai Saluesem yaitu 0,222. Di bagian hilir, nilai indeks dominansi yaitu Stasiun I $(0,534)$ dan Stasiun II (0,556). Nilai Indeks dominansi fitoplankton di bagian hilir Sungai Saluesem yaitu 0,544 (Gambar 4).

Hasil penelitian menunjukan fitoplankton di bagian tengah tidak ada yang dominan dengan nilai indeks $\mathrm{D}$ mendekati angka nol. Beberapa species fitoplankton di bagian hilir cenderung dominan dengan nilai indeks D mendekati angka satu. Indeks dominansi yang rendah ini disebabkan karena keanekaragaman di Sungai Saluesem masuk dalam kategori sedang menurut kriteria Fachrul (2007). Nilai indeks dominansi berbanding terbalik dengan keanekaragaman 
sehingga jika indeks dominansi tinggi maka indeks keanekaragamannya rendah dan sebaliknya.

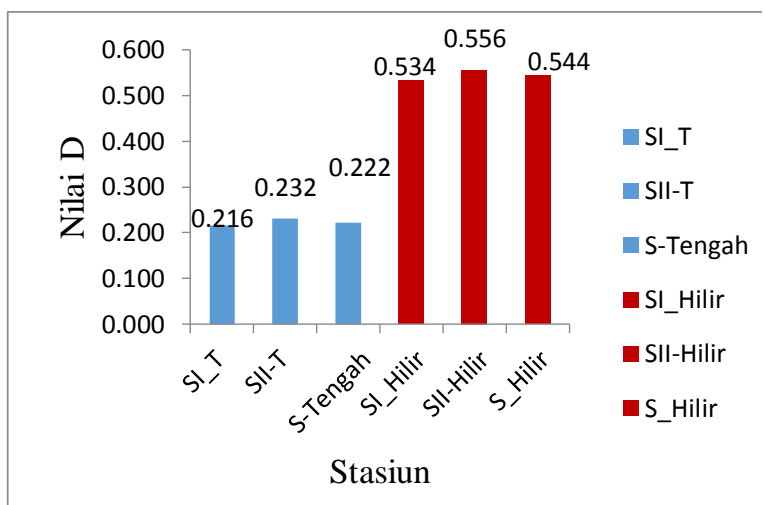

Gambar 4. Nilai Indeks Dominansi di Bagian Tengah dan Hilir Sungai Saluesem

\section{KESIMPULAN}

Berdasarkan hasil penelitian dapat disimpulkan bahwa Fitoplankton yang didapatkan di bagian tengah Sungai Saluesem sebanyak 399 individu, 28 spesies dan 3 kelas. Fitoplankton yang didapatkan di bagian hilir Sungai Saluesem sebanyak 913 individu, 26 spesies dan 4 kelas. Fitoplankton yang ditemukan di bagian tengah berjumlah 3 kelas yaitu Kelas Bacillariophyceae, Chlorophyceae dan Cyanophyceae. Fitoplankton yang ditemukan di bagian hilir sejumlah 4 kelas yang sama dengan di bagian tengah dengan penambahan Kelas Euglenophyceae. Kelas Bacillariophyceae merupakan kelas yang memiliki kepadatan tertinggi di bagian tengah dan hilir berturutturut yaitu 4067 individu $/ \mathrm{m}^{3}(81 \%)$ dan $14950 \quad$ individu $/ \mathrm{m}^{3} \quad(95 \%)$. Indeks keanekaragaman di bagian tengah dan hilir termasuk keanekaragaman sedang dengan nilai $\mathrm{H}^{\prime}$ bagian tengah ( $\left.\mathrm{H}^{\prime}: 2,88\right)$ dan bagian hilir (H': 2,64). Distrubusi species fitolankton di bagian tengah dan hilir merata dengan Indeks Kemerataan (E) 0,87 dan 0,81. Fitoplankton di bagian tengah tidak ada yang dominan dengan Nilai indeks dominansi (D) yaitu 0,222. Beberapa species fitoplankton di bagian hilir cenderung dominan dengan nilai Indeks D mendekati satu $(0,544)$.

\section{DAFTAR PUSTAKA}

Asriyana \& Yuliana. 2012. Produktivitas Perairan. Bumi Aksara, Jakarta.
Bold, H. C \& M J. Wynne. 1985. Introduction to the Algae. Second Edition. Prentice-Hall, Inc., London.

Edmondson, W T. 1966. Freshwater Biology. Secound Edition. University of Washington, Seattle.

Fachrul, M.F. 2007. Metode Sampling Bioekologi. Bumi Aksara, Jakarta.

Magurran, A E. 2004. Measuring Biological Diversity. Blackwell Publishing, Victoria.

Nontji, A. 2008. Plankton Laut. Lembaga Ilmu Pengetahuan Indonesia Press, Jakarta.

Odum, E.P. 1993. Dasar-dasar Ekologi. Gajah Madah University Press, Yogyakarta.

Sachlan, M. 1982. Planktonologi. Fakultas Perternakan dan Perikanan Universitas Diponegoro, Semarang.

Van Den Hoek. C., D G. Mann \& H N.Johns. 1995. Algae an Introduction to Pycology. Cambridge University Press, New York.

Wardhana, W.A. 2004. Dampak Pencemaran Lingkungan. Andi Yogyakarta, Yogyakarta.

Wilhm, J.L.1975. Biological Indicators of Pollution dalam River Ecology. B.A Whitton (ed.). Blackwell Scientific Publication. Oxford. pp: 375-402. 